\title{
CONCERNING THE NATURALLY OCCURRING PORPHYRINS. IV. THE URINARY PORPHYRIN IN LEAD POISONING AS CON- TRASTED WITH THAT EXCRETED NORMALLY AND IN OTHER DISEASES ${ }^{1}$
}

\author{
By CECIL JAMES WATSON \\ (From the Department of Medicine, University of Minnesota Hospital, Minneapolis)
}

(Received for publication January 22, 1936)

In previous communications $(1,2,3)$, the literature relating to $\mathrm{H}$. Fischer's "dualism" of the natural porphyrins was discussed. The isolation of coproporphyrin I from the urine of a patient with cincophen cirrhosis of the liver, also from the feces in hemolytic jaundice and pernicious anemia, was reported. Of particular interest was the consideration of these findings with relation to the clinical and experimental observations of Van den Bergh and coworkers $(4,5)$. These investigators pointed out that human erythrocytes regularly contain protoporphyrin which is increased in amount in the same individuals who exhibit increases of coproporphyrin in the urine. By perfusion experiments they further demonstrated that the surviving liver of the dog is able to convert protoporphyrin into coproporphyrin. Correlation of these studies made it appear likely that the coproporphyrin of the urine, as well as of the bile, may originate from the protoporphyrin of the erythrocytes. Since hemoglobin, following loss of its protein and iron, yields a protoporphyrin of the aetioporphyrin III type (6), it was naturally assumed that the porphyrins of the urine and bile are directly related to hemoglobin metabolism. Schreus (7) in particular has pointed to Van den Bergh's results as supporting this conception. The idea that the porphyrin of the urine is derived from hemoglobin is by no means a recent one. In fact, a considerable literature dealing with this question was collected by Garrod in 1900 (8). Although Garrod subscribed to the belief that the urinary porphyrin, then spoken of as hematoporphyrin, was related to hemoglobin destruction, he observed that increases in amount were frequently associated with clinical or anatomical evidence of liver disease.

1 Aided by a grant from research funds of the Graduate School of the University of Minnesota.
The concept that the coproporphyrin of the urine and bile is derived from hemoglobin was not supported by the findings described in Parts I to III of this investigation $(1,2,3)$. The occurrence of coproporphyrin I rather than III constituted evidence that at least in the instances studied, porphyrin formation was a process distinctly separate from the synthesis or destruction of hemoglobin. The isolation of coproporphyrin III from the urine in lead poisoning was described by Grotepass (9), later by H. Fischer and Duesberg (10). Since ordinary hemin and coproporphyrin III both correspond in configuration to aetioporphyrin III, the elaboration of coproporphyrin III in lead poisoning could be associated quite readily with a peculiar disturbance in hemoglobin metabolism.

The function of the porphyrins present in the erythrocytes, urine, bile and feces is quite unknown and can hardly be determined until exact knowledge of their origin and isomeric type is obtained. The amount of porphyrin in normal urine is so small that it has not yet been isolated, and the important question as to whether it is coproporphyrin I or III remains unanswered. The finding of coproporphyrin $I$ in the urine in an instance of advanced liver disease (1), suggested that it was the normal urine porphyrin, increased in amount for the same reason that urobilinogen was increased, i.e., diminished excretory function of the liver.

The purpose of the present investigation was to isolate and identify the coproporphyrin of a normal urine, and of the urine in some of the pathological states accompanied by a heightened porphyrin excretion; further, to determine whether coproporphyrin III is regularly excreted in the urine in lead poisoning (as yet it has been isolated but from one instance). 


\section{MATERIAL AND METHODS}

The entire amount of urine for a period of 33 days was collected from a healthy male student ${ }^{2}$ 18 years of age. As soon as 2 to 3 liters had accumulated the specimen was subjected to the procedure previously described (1), with the following exceptions. In each instance the primary ether extract after washing with water was repeatedly extracted with small amounts of 10 per cent $\mathrm{HCl}$. The 10 per cent $\mathrm{HCl}$ solutions were united and kept in the refrigerator during the period of further collection and primary extraction of the urine. All of the hydrochloric acid extract was then covered with a large amount of ether, an excess of sodium acetate was added, and the mixture at once vigorously shaken. Having made certain that the aqueous fraction was negative to Congo paper, ether extraction was repeated until the porphyrins were removed completely. The further treatment of this solution of ether was the same as described previously (1). The final coproporphyrin solution in ether was not dried over sodium sulphate as was done previously, since it has been found to be true that a moderate loss of porphyrin occurs by adsorption on this salt. This was first noted by H. Fischer and Zerweck (11). The ether was simply decanted into a dry flask and was then removed completely upon the water bath. The porphyrin residue after drying in the air was esterified with $\mathrm{HCl}$ in methyl alcohol, and the ester was crystallized from chloroform-methyl alcohol in the usual way (1).

Employing the same method, porphyrin esters were isolated from the urines of the following cases.

Case 1. Fever. Male, 37 years of age with lung abscess and empyema. The daily elevation of temperature ranged from 101 to $103^{\circ} \mathrm{F}$. Urobilinuria was 8.3 mgm. urobilinogen per day (23). There was no jaundice. Moderate anemia was present, and hemoglobin was 55 per cent (Sahli method, 17 grams per 100 cc. equivalent to 100 per cent). Urine was collected for a period of 12 days.

Case 2. Acquired hemolytic jaundice. Female, 18 years of age with slight icterus, without anemia, of 3 years' duration, increasing icterus and anemia, 4 months.

2 The writer is indebted to Mr. Samuel Schwartz for the collection and preliminary extraction of this urine.
Hemoglobin was 32 per cent (Sahli), erythrocytes 1,150 ,000 per $\mathrm{cu} . \mathrm{mm}$. Stained smears revealed marked macroanisocytosis, polychromatophilia. Reticulocytes varied between 15 and 32 per cent. Resistance of erythrocytes to hypotonic saline was as follows: $\mathrm{H}_{1} .38, \mathrm{H}_{2} .32$, control $\mathrm{H}_{1} .38, \mathrm{H}_{2} .30$.

There was marked autoagglutination of erythrocytes in vitro (below $30^{\circ} \mathrm{C}$.), the icterus index was 30 , and the Van den Bergh reaction was of the indirect type. Feces urobilinogen: $1106 \mathrm{mgm}$. per day. (Normal range 100 to 250.) Urine urobilinogen $2.5 \mathrm{mgm}$. per day. (Normal range 0.5 to 3.0 .) (23)

Physical examination revealed nothing except a smooth cystic mass in the left side of the pelvis. The spleen and liver were not palpable. It was considered possible that chronic hemorrhage into an ovarian cyst with local formation of bilirubin might be responsible for the findings described above. Consequently the cyst was removed at operation. It contained $800 \mathrm{cc}$. of a dark brown fluid rich in hematin (identified by hemochromogen spectrum after treatment with ammonium sulphide). Bilirubin and porphyrins were not identified, although searched for.

There was no improvement following this operation. On the contrary, icterus and anemia increased, and there was moderate fever. The urobilinogen in the urine increased markedly for a few days after operation, then decreased rapidly again. The highest value noted was $380 \mathrm{mgm}$. per day. During this period the urine was examined for porphyrins and a considerable increase of coproporphyrin was observed.

After an interval of three weeks during which the patient's condition remained precariously stationary, splenectomy was carried out. The spleen weighed but 460 grams, exhibiting microscopically a marked pulp congestion. The liver appeared to be entirely normal. This operation was followed by prompt improvement. Two months after operation the hemoglobin was 70 per cent (Sahli), the icterus index 10, and the feces urobilinogen $206 \mathrm{mgm}$. per day. Eight months later the patient reported that she felt entirely well and that there was no jaundice.

The urine employed for the isolation of coproporphyrin consisted of the entire amount for a period of four days immediately following the first operation (coincident with the highest urobilinogen excretion). This urine was first employed for the isolation of crystalline urobilinogen, a procedure which will be described elsewhere (24). Suffice it to say that this entailed a preliminary extraction with petroleum ether in which coproporphyrin is insoluble. Following this, the coproporphyrin was extracted with ether in the manner already referred to (1). It is worthy of note that this urine contained another pigment resembling bilirubin, but differing from it in that it failed to give a Gmelin test as well as the more delicate reaction for bilirubin devised by Harrison, and described by Godfried (12). Also differing from bilirubin the substance could not be extracted with chloroform from the urine. However, it gave a delayed and an indirect Van den Bergh reaction, and was precipitated by a barium chlo- 
ride solution. In dilute $\mathrm{NaOH}$ ill defined absorption between 536 to $477 \mathrm{~m} \mu$ was observed. Attempts to crystallize the substance were unsuccessful, probably because of its obvious lability, and it can only be stated that its characteristics as noted above appeared to be those of the "hämorubin" of Jenke (13), which, it is noteworthy, was likewise obtained from the urine of an individual with hemolytic jaundice.

Casc 3. Lead poisoning. Male, 67 years of age. Mild anemia, hemoglobin 69 per cent. Considerable basophilic stippling of erythrocytes. Urine collection for a period of 5 days.

Case 4. Lead poisoning. Male, 46 years of age. Colic, anemia, hemoglobin 66 per cent, marked basophilic stippling of erythrocytes. Urine collection for a period of 4 days.

Case 5. Lead poisoning. Male, 38 years of age. Weakness of extensor muscles, mild anemia, hemoglobin 67 per cent, considerable basophilic stippling of the erythrocytes. Urine collection over a period of 6 days.

Cases 3, 4 and 5 were members of a large group of foundry employees suffering from lead poisoning. ${ }^{3} \quad$ The bearings in this foundry contained lead and were believed responsible for the numerous instances of lead poisoning which were encountered.

The total amount of urine collected in each of the above instances was subjected to the method of isolation already referred to. It is important to note that the fractionation of porphyrins embodied in this method depends upon characteristic solubilities $(1,2)$. Consequently, the coproporphyrins isolated and described in the following paragraphs possessed in each instance the typical solubilities of a coproporphyrin, particularly in not leaving 0.2 per cent $\mathrm{HCl}$ for chloroform. The sodium salt in each instance was entirely soluble in 10 per cent $\mathrm{NaOH}$, a further characteristic of coproporphyrins.

Spectroscopic studies were carried out by means of apparatus and methods described previously $(1,2)$. Slight variations in the maxima for the absorption bands of the coproporphyrins isolated will be noted, if compared with those observed before $(1,2,3)$. Since the spectrometer was not

3 The writer is indebted to Dr. E. C. Emerson of St. Paul, Minnesota, for the opportunity to investigate the urine of these cases. recalibrated, these are believed attributable to very slight changes in the relation of the wave length scale of the instrument to its grating. Of chief importance is the identification by means of superimposition of spectra, employing a pure coproporphyrin to compare with that under investigation. With the apparatus used (1), this permits detection of the slightest differences in position of absorption bands.

\section{RESLLTS (SEE TABLF I)}

\section{Normal urine}

After four recrystallizations $0.13 \mathrm{mgm}$. of porphyrin ester were oltained from 33 days' normal urine. This will be spoken of as Fraction a. The ester composing this fraction crystallized rapidly in the form of fluffy masses consisting of fine curving and branching needles. This manner of crystallization is very characteristic of coproporphyrin I ester while coproporphyrin III ester crystallizes much more slowly in smaller clumps of crystals often adhering to the walls of the tube. These have the form of needle-like prisms which are usually broader than those of coproporphyrin I, and do not show the curving and branching of the latter. The crystals of coproporphyrin III ester rather frequently arrange themselves in concentrically united groups, or rosettes $(10,14,15,16)$. During crystallization and first recrystallization of Fraction a, it was observed that the mother liquor obviously contained more porphyrin than is usually true when coproporphyrin I ester is crystallized from chloroform methyl alcohol. These two mother liquors were combined and allowed to concentrate slowly at room temperature. After standing several days a further separation of crystals appeared. These were in the form of small aggregates part of which adhered to the walls of the small test tube in which the solution was contained. This material will be spoken of as Fraction b; its amount was evidently considerably less than that of Fraction a, nevertheless it was possible to recrystallize it twice in orcler to further observe its manner of crystallization; the amount did not suffice for a melting point cletermination. The characteristics of these fractions were as follows. 

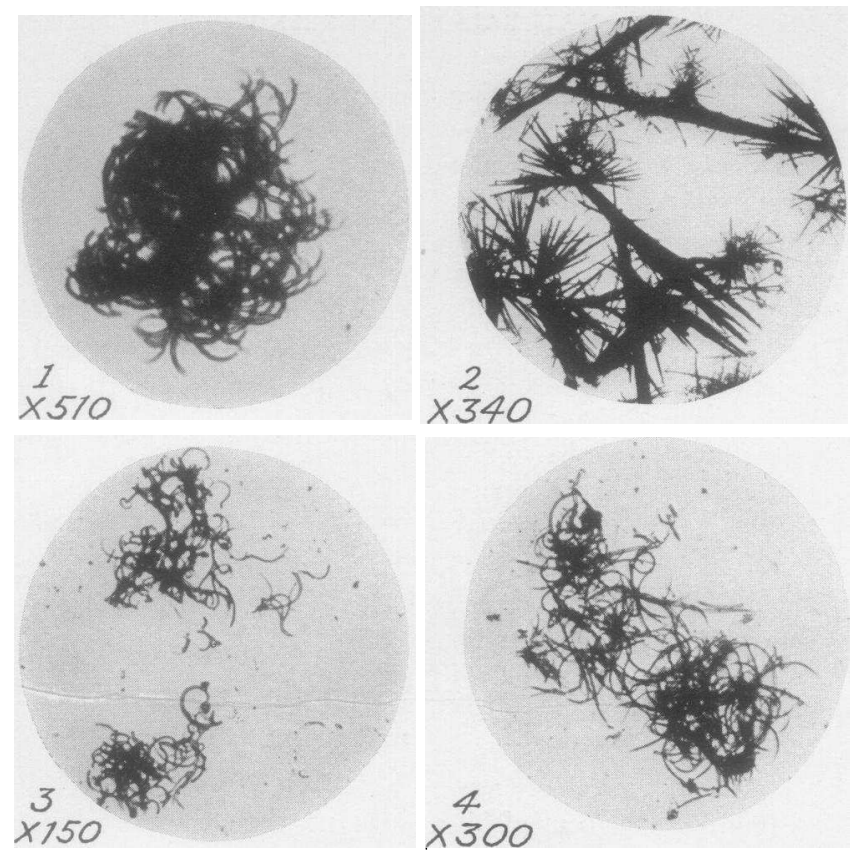

$5 a$

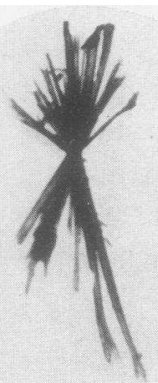

$\times 150$

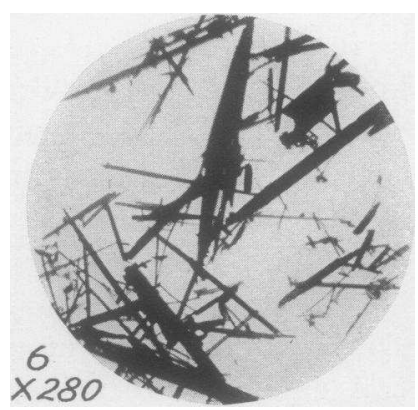

$5 b$

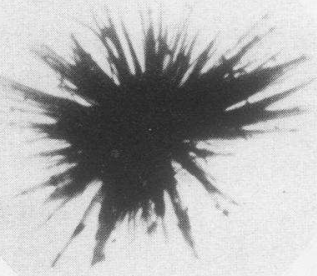

$\times 150$

Fig. 1. Coproporphyrin I Ester from Normal Urine.

Fig. 2. Coproporphyrin Ester from Normal Urine, Crystal Form Suggestive of Coproporphyrin III.

Fig. 3. Coproporphyrin I Ester from Urine of Patient with Fever Due to Lung Abscess and Empyema.

Fig. 4. Coproporphyrin I Ester from Urine of Patient with AcQuired Hemolytic Jaundice.

Fig. 5. Coproporphyrin III Ester from Urine of First Case of Lead Poisoning.

Fig. 6. Coproporphyrin III Ester from Urine of SeCond Case of Llead Poisoning.

Fig. 7. Coproporphyrin III Ester from Urine of Third Case of Lead Poisoning. 
Fraction a. The crystals had the form of long curving needles (Figure 1). On recrystallization these appeared rather quickly in the light fluffy clumps characteristic of coproporphyrin I ester. After four recrystallizations the amount $(0.13$ mgm.) sufficed for one melting point determination. The substance did not melt sharply; shrinking was observed above $190^{\circ}$, melting from 218 to $223^{\circ}$. (Coproporphyrin I methyl ester, for which the writer is indebted to Professor $\mathrm{H}$. Fischer in Munich, melted at 245 to $246^{\circ}$ C.) No change whatever was exhibited at the lower temperatures critical for coproporphyrin III ester $\left(142^{\circ}, 172^{\circ}\right)$. The absorption spectrum in acetic and ether solution was: I. $\frac{627.8-622.2}{624.8}$; II. faint maximum 597.5 ; III. $\frac{582.7-568.3}{577.4}$; IV. $\frac{533.5-526.0}{530.0}$; V. $\frac{507.0-487.0}{496.6}$. Order of intensity: V, IV, I, III, II. This was identical with the superimposed absorption spectrum of known coproporphyrin I in similar solution.

Fraction b. The crystals of this fraction appeared very slowly in the manner already referred to. The majority of the crystals were long narrow prisms similar to those of coproporphyrin III ester; a few curved and branching needles of the coproporphyrin I type were also noted. After two recrystallizations the appearance of crystals was still delayed and not prompt as is usual with even very small amounts of coproporphyrin I ester. The crystals now appeared to be uniform in type, namely, needle-like prisms frequently in groups (Figure 2), strongly suggestive of coproporphyrin III methyl ester. Spectroscopically this material was a coproporphyrin, having the following absorption spectrum: I. $\frac{627.1-622.3}{624.9}$; II. faint maximum $597.9 ;$ III. $\frac{581.8-568.0}{577.2} ;$ IV. $\frac{534.0-525.2}{531.0}$; V. $\frac{505.7-487.7}{496.9}$. Order of intensity: V, IV, I, III, II. This was identical with the superimposed spectrum of a similar solution of coproporphyrin I.

\section{Pathological urines}

Case 1. Fever due to lung abscess and empyema. After three recrystallizations $1.5 \mathrm{mgm}$. of porphyrin ester were obtained. This crystallized rapidly in the manner of coproporphyrin $I$, and the individual crystals were fine curving needles (Figure 3). The melting point was 204 to $208^{\circ}$ C. The remaining substance was recrystallized twice more, following which the melting point was 215 to $218^{\circ} \mathrm{C}$. All that remained was now mixed with coproporphyrin I methyl ester of melting point 245 to $246^{\circ} \mathrm{C}$., in an approximate ratio of one part of the former to four of the latter. The melting point of this mixture was 240 to $243^{\circ} \mathrm{C}$. From this it is evident that while the porphyrin isolated was still slightly impure, it melted far above the melting point of coproporphyrin III ester, and did not depress the melting point of known coproporphyrin I ester suffciently to suggest that it was another porphyrin. The absorption spectrum was that of a coproporphyrin, i.e., I. $\frac{626.7-622.2}{624.8}$; II. $\frac{583.3-567.6}{577.8}$; III. $\frac{534.9-525.5}{530.9}$; IV. $\frac{506.4-490.3}{497.5}$. Order of intensity: IV, III, I, II. This absorption was identical with that of coproporphyrin I when the spectra were superimposed in the comparison spectrometer.

During the isolation of the above coproporphyrin it was noted that another porphyrin remained in the ether and was not extracted by 1 per cent $\mathrm{HCl}$, but was removed quantitatively by 10 per cent $\mathrm{HCl}$. This porphyrin was chloroform soluble, and was readily removed from $\mathrm{HCl}$ solutions by chloroform. The amount was too small to be obtained in a crystalline form; it was possible, however, to examine the substance spectroscopically. The acetic and ether solution was bluish pink and exhibited the following absorption: I. $\frac{634.7-625.6}{631.5}$; II. $\frac{598.0-571.9}{580.9}$; III. $\frac{554.8-530.5}{536.6}$; IV. $\frac{514.8-492.0}{502.3}$. Order of intensity : IV, III, I, II. This absorption spectrum is quite characteristic of protoporphyrin (15), and in fact complete identity with protoporphyrin was observed when the spectra were superim- 
posed. This confirms the report of Boas (17) regarding the occasional finding of protoporphyrin in the urine.

Case 2. Acquired hemolytic jaundice. The yield of porphyrin ester was $0.6 \mathrm{mgm}$. This crystallized rapidly in the fluffy masses of long curving needles characteristic of coproporphyrin I ester (Figure 4). The melting point after five recrystallizations was 235 to $238^{\circ} \mathrm{C}$. with considerable shrinking above $220^{\circ}$. A mixture with approximately equal parts of coproporphyrin I ester (melting point 245 to $246^{\circ}$ ), also melted at 236 to $238^{\circ} \mathrm{C}$., but with less preceding shrinking.

The absorption spectrum of this porphyrin in acetic and ether solution was as follows: I. $\frac{626.4-622.7}{624.7}$; II. faint maximum 596.1; III. $\frac{581.2-567.5}{577.5}$; IV. $\frac{535.2-524.9}{531.3}$; V. $\frac{506.8-486.2}{496.3}$. Order of intensity: V, IV, I, III, II. This was identical with the superimposed absorption spectrum of coproporphyrin I in a similar solution.

Case 3. Lead poisoning. One milligram porphyrin ester after 3 recrystallizations. This crystallized slowly in the characteristic manner of coproporphyrin III (Figures $5 \mathrm{a}$ and $5 \mathrm{~b}$ ). The melting point was 161 to $164^{\circ} \mathrm{C}$. The remaining material was recrystallized once after which the melting point was 164 to $166^{\circ}$. The amount of substance did not suffice for another recrystallization. H. Fischer $(6,16)$ observed that coproporphyrin III methyl ester exhibits a double melting point probably dependent upon tautomerism. At times the ester melts at $142^{\circ}$, again at $172^{\circ}$. (H. Fischer, Platz and Morgenroth (16) in studying synthetic coproporphyrin III observed melting points of the first tautomer between 144 and $148^{\circ}$ even after several recrystallizations.) The absorption spectrum in acetic and ether solution was as follows: I. $\frac{624.7-621.0}{623.6}$; II. weak at maximum 596.6; III. $\frac{581.3-567.1}{577.1}$; IV. $\frac{532.5-524.3}{529.5} ;$ V. $\frac{505.8-483.8}{495.5}$. Order of intensity: V, IV, I, III, II. Superimposed with coproporphyrin $I$ in the comparison spectrometer there was almost, if not entire identity of the spectra. (Questionable difference in position of Band I.) It should be noted that the absorption spectra of all four isomeric coproporphyrins have been shown to be identical (16).

Case 4. Lead poisoning. There were 4.1 mgm. porphyrin ester after 3 recrystallizations. Crystallized slowly in the manner characteristic of coproporphyrin III (Figure 6). After another recrystallization the substance melted at $156^{\circ}$, with marked shrinking above $146^{\circ}$. After a fifth recrystallization, the melting point was 147 to $150^{\circ}$, and after a sixth, 144 to $149^{\circ}$. A small amount of the latter material was submitted to Prof. Hans Fischer in Munich for whose report the writer wishes to acknowledge his gratitude. "The mixed melting point (with coproporphyrin III ester) gave no depression. The crystal form of the concentrically united needles is characteristic of coproporphyrin III."

The material exhibited the spectroscopic absorption of a coproporphyrin, as follows: I. $\frac{626.7-622.6}{624.8}$; II. $\frac{583.5-567.5}{577.0}$; III. $\frac{534.6-525.3}{531.3}$; IV. $\frac{507.1-489.3}{496.9}$. Order of intensity: IV, III, I, II. With the absorption spectra superimposed in the usual way, complete identity with coproporphyrin I was noted.

TABLE I

Summary of results

\begin{tabular}{|c|c|c|c|c|}
\hline Source of urine & $\begin{array}{l}\text { Num- } \\
\text { ber of } \\
\text { days } \\
\text { collec- } \\
\text { tion }\end{array}$ & $\begin{array}{l}\text { Amount } \\
\text { of erys- } \\
\text { talline } \\
\text { ester } \\
\text { obtained }\end{array}$ & Crystal type & $\begin{array}{l}\text { Melting } \\
\text { point }\end{array}$ \\
\hline 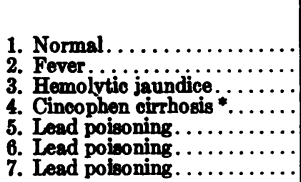 & $\begin{array}{r}33 \\
12 \\
4 \\
8 \\
5 \\
6 \\
4\end{array}$ & $\begin{array}{l}\text { mom. } \\
0.13+ \\
1.5 \\
0.6 \\
1.2 \\
1.0 \\
1.4 \\
4.1\end{array}$ & $\begin{array}{l}\text { Coproporphyrin I } \\
\text { Coproporphyrin I } \\
\text { Coproporphyrin I } \\
\text { Coproporphyrin I } \\
\text { Coproporphyrin III } \\
\text { Coproporphyrin III } \\
\text { Coproporphyrin III }\end{array}$ & $\begin{array}{c}\text { o } C . \\
218 \text { to } 223 \\
215 \text { to } 218 \\
235 \text { to } 238 \\
241 \text { to } 243 \\
164 \text { to } 166 \\
143 \text { to } 144 \\
141 \text { to } 149\end{array}$ \\
\hline
\end{tabular}

* This instance, described previously (1), is included here for purposes of comparison.

Case 5. Lead poisoning. There were $1.4 \mathrm{mgm}$. porphyrin ester after 3 recrystallizations. Crystallized slowly in small aggregations of long, narrow, well defined prisms (Figure 7). Melting point 143 to $144^{\circ}$. The following absorption spectrum was observed: I. $\frac{627.5-623.0}{625.3}$; II. 
faint maximum 607.7 ; III. $\frac{583.0-568.2}{577.6}$; IV. $\frac{535.6-525.4}{530.9}$; V. $\frac{507.7-485.5}{487.1}$. Order of intensity: V, IV, I, III, II. There was complete identity of absorption spectra when superimposed with coproporphyrin I in acetic and ether solution.

\section{COMMENT}

Although most of the porphyrin obtained from the normal urine was evidently coproporphyrin I, a very small fraction crystallized in the manner of coproporphyrin III ester, and it is believed probable that coproporphyrin III was actually present in an extremely small proportion. In this connection the earlier observations of Schumm (18) and H. Fischer $(16,19)$ must be mentioned. These concerned the increase of urinary coproporphyrin after ingestion of blood or blood containing foods. It is entirely conceivable that coproporphyrin III might originate from protoporphyrin (16) derived from hemoglobin in the bowel, and it is equally conceivable that the coproporphyrin content of the urine might be increased in this way (16). The normal individual whose urine was used in the above investigation was not restricted as to diet, and ate considerable meat throughout the period of collection of the urine, so that small amounts of hemoglobin may have been supplied. The fact remains, however, that the great majority of the porphyrin isolated had the characteristics of coproporphyrin I, and coproporphyrin III, if present, was in much smaller amount. It is quite possible that the melting point of Fraction a, i.e., of the crystals of coproporphyrin I type, was lowered because of the presence of traces of coproporphyrin III. This possibility may also account for the lowering in other of the instances noted above where the crystal form was that of coproporphyrin I. H. Fischer, Platz, and Morgenroth (16) noted instances where natural coproporphyrin I ester could not be brought to a melting point of over $240^{\circ} \mathrm{C}$. even after repeated recrystallization; they observed that this was also true in the case of an artificial mixture of coproporphyrin I and coproporphyrin III esters. In this connection it is believed significant that the melting points were higher in the present instances (such as 3 and 4 in the above table) where much smaller amounts of urine were necessary for the isolation of the coproporphyrins.

In instances 2, 3 and 4, above, all of the porphyrin ester obtained had the crystal form characteristic of coproporphyrin I, and crystals of the coproporphyrin III type were not obtained by further concentration of the mother liquors. The opposite was true in instances 5, 6 and 7 .

In this investigation no attempt to isolate a uroporphyrin was made. This porphyrin is insoluble in ether and according to H. Fischer (6) is formed secondarily from coproporphyrin.

It is noteworthy that in each of the above cases, 2 to 4 , urobilinogen was considerably increased in the urine, this lending some support to the statement made previously (1) that coproporphyrin I may increase in the urine because of diminished hepatic excretory function.

The above findings reveal that coproporphyrin I is of rather frequent occurrence in the urine, while coproporphyrin III has so far been identified with certainty only in lead poisoning and rare instances of congenital porphyrinuria (1).4 The significance of the occurrence of coproporphyrin I in the urine is not yet clear; the possibility that it is exogenous has already been mentioned, and some evidence against this view was presented (1, $2,3)$. The question of the origin and significance of the coproporphyrin in the urine, bile and feces will be discussed in more detail in a later communication.

\section{SUM MARY}

Coproporphyrin I has been isolated from the urine of a normal individual. It is probable that relatively very small amounts of coproporphyrin III were likewise present. Coproporphyrin I was obtained in much larger amount from the urine of an individual with fever due to pulmonary suppuration, and from a patient with hemolytic jaundice during a postoperative " hemoclastic" crisis. In both of the latter instances considerable increases in the urine urobilinogen

4 Hoerburger and Fink (20) have recently isolated a coproporphyrin from the urine of a patient treated with salvarsan (no mention of jaundice). Because of the type of crystal and the $\mathrm{pH}$ fluorescence curve they believed this to be coproporphyrin III. The significance of this finding will not be clear until further studies of porphyrin excretion following salvarsan treatment have been made. 
were observed simultaneously with the heightened excretion of coproporphyrin. A porphyrin was isolated from the urine in three cases of lead poisoning. The crystal form and melting point of the ester indicated clearly that this was, in each instance, coproporphyrin III.

Since this communication was submitted for publication, an important finding of Hoerburger's, mentioned in his inaugural dissertation (21), has come to the writer's attention. Hoerburger isolated a crystalline coproporphyrin from normal urine; the crystal form and $\mathrm{pH}$ fluorescence curve (22) were characteristic of coproporphyrin I. The amount obtained was presumably too small for determination of the ester melting point.

An extensive study of the urinary porphyrins has recently been reported by Dobriner (25). Coproporphyrin I was obtained in a variety of diseases, including hemolytic jaundice and pulmonary infection; this finding is confirmed in the present report. Dobriner found coproporphyrin $I$ in the urine in a number of instances of liver disease, which is in keeping with the writer's previous report concerning cincophen cirrhosis. In this connection it is of considerable interest that Dobriner found coproporphyrin III in one instance of atrophic cirrhosis, and in one of pigment cirrhosis.

\section{BIBLIOGRAPHY}

1. W-atson, C. J., Concerning the naturally occurring porphyrins. I. The isolation of coproporphyrin I from the urine in a case of cincophen cirrhosis. J. Clin. Invest., 1935, 14, 106.

2. Watson, C. J., Idem, II. The isolation of a hitherto undescribed porphyrin occurring with an increased. amount of coproporphyrin I in the feces of a case of familial hemolytic jaundice. J. Clin. Invest., $1935,14,110$.

3. Watson, C. J., Idem, III. The isolation of coproporphyrin I from the feces of untreated cases of pernicious anemia. J. Clin. Invest., 1935, 14, 116.

4. Van den Bergh, A. A. H., and Hyman, A. J., Studien über Porphyrin. Deutsche med. Wchnschr., 1928, 54, 1492.

5. Van den Bergh, A. A. H., Grotepass, W., and Revers, F. E., Beitrag über das Porphyrin in Blut und Galle. Klin. Wchnschr., 1932, 11, 1534.

6. Fischer, H., Farbstoffe mit Pyrrolkernen. A. Ueber Blut, Blatt und Gallenfarbstoffe. Oppenheimer's Handb. der Biochem, des Menschen u. der Tiere. Zweite Auflage. Ergänzungsband. G. Fischer, Jena, 1930, p. 72.
7. Schreus, H. T., Ergebnisse und Probleme der Porphyrinforschung. Klin. Wchnschr., 1934, 13, 121.

8. Garrod, A. E., The urinary pigments in their pathological aspects. Lancet, 1900, 2, 1323.

9. Grotepass, W., Zur Kenntnis des im Harn auftretenden Porphyrins bei Bleivergiftung. Ztschr. f. physiol. Chem., 1932, 205, 193.

10. Fischer, H., and Duesberg, R., Uber Porphyrine bei klinischer und experimenteller Porphyrie. Arch.f. exper. Path. u. Pharmakol., 1932, 166, 95.

11. Fischer, H., and Zerweck, W., Zur Kenntnis der natürlichen Porphyrine. V. Uber Koproporphyrin im Harn und Serum unter normalen und pathologischen Bedingungen. Ztschr. f. physiol. Chem., 1924, 132, 12.

12. Godfried, E. G., Clinical tests for bilirubin in urine. Biochem. J., 1934, 28, 2056.

13. Jenke, M., Uber die Natur des indirekten Bilirubins (Hämorubin). Verhandl. d. deutsch. Gesellsch. f. inn. Med., 1931, 43, 387.

14. Fischer, H., Hilmer, H., Lindner, F., and Pützer, B., Zur Kenntnis der natürlichen Porphyrine. XVIII. Chemische Befunde bei einem Fall von Porphyrinurie (Petry). Ztschr. f. physiol. Chem., 1925, 150, 44.

15. Kirstahler, A., Blutfarbstoff und Derivate. Tabulae Biologicae Periodicae, 1931, Bd. VII, 48.

16. Fischer, H., Platz, K., and Morgenroth, K., Synthese von Koproporphyrin III und IV, ein Beitrag zur Kenntnis der Porphyrie. Ztschr. f. physiol. Chem., 1929, 182, 265.

17. Boas, I., Uber das Vorkommen von Protoporphyrin im Harn. Klin. Wchnschr., 1933, 12, 589.

18. Schumm, $O$., Uber die natürlichen Porphyrine. Ztschr. f. physiol. Chem., 1923, 126, 169.

19. Fischer, H., Farbstoffe mit Pyrrolkernen. Oppenheimer's Handb. der Biochem, des Menschen u. d. Tiere, Zweite Auflage, Band I, Baustoffe der tierischen Substanz. G. Fischer, Jena, 1924, p. 351.

20. Hoerburger, W., and Fink, H., Ueber Porphyrine bei klinischer Porphyrie. Ztschr. f. physiol. Chem., 1935, 236, 136.

21. Hoerburger, W., Zur Kenntnis der Porphyrinfluoreszenz und deren Anwendung bei physiologischen Untersuchungen. Inaug. Diss. Erlangen, 1933.

22. Fink, H., and Hoerburger, W., Isolierung von kristallisiertem Koproporphyrin I aus normalen menschlichem Urin. Die Naturwissenschaften, 1934, 18, 292.

23. Watson, C. J., Studies of urobilinogen. II. Urobilinogen in the urine and feces of individuals without evidence of disease of the liver or biliary tract. III. Urobilinogen excretion in the common forms of jaundice and liver disease. Arch. Int. Med. (In press).

24. Watson, C. J., The origin of natural crystalline urobilin (stercobilin). J. Biol. Chem. (In press).

25. Dobriner, K., Urinary porphyrins in disease. J. Biol. Chem., 1936, 113, 1. 